\title{
Memorial for Seymour S. Kety
}

Seymour S. Kety died May 25, 2000. I was privileged to have known him for 56 years as teacher, preceptor, collaborator, colleague, and friend. In all these roles he was exemplary. He graced every field in which he worked and those with whom he worked. I know of no scientist as universally respected, admired, and loved.

He was born in Philadelphia, August 25, 1915, and raised there in humble but intellectually stimulating surroundings. His normal inclination toward intellectual pursuits was enhanced by a physical limitation derived from an automobile-inflicted injury in his childhood. He was educated in Philadelphia where he attended Central High School, the city's premier high school, and the college and medical school of the University of Pennsylvania. He graduated from medical school in 1940 and then interned at the Philadelphia General Hospital where he made his first major contribution to medical science, chelation treatment of lead poisoning with citrate.

After internship Seymour obtained an NRC fellowship to continue work on lead poisoning with Joseph Aub at the Massachusetts General Hospital, Boston. Aub was well known in this field, but in 1942 the U.S. was at war, and Aub had switched to research on traumatic and hemorrhagic shock. Seymour, therefore, also worked on shock and became interested in the physiology of the circulation, particularly of the brain. After two years with Aub he returned to Penn as an Instructor in the Dept. of Pharmacology which was headed by Carl Schmidt, a leading researcher on the cerebral circulation. I first met Seymour in 1944 as a member of his first class in pharmacology. He was a stimulating and popular teacher whose lectures were always lucid and emphasized experimental procedures and findings underlying conclusions. He

Address correspondence to: Dr. Louis Sokoloff, Laboratory of Cerebral Metabolism, National Institute of Mental Health, Building \#36, Room 1A-07, Bethesda, MD 20892, USA, Tel.: 301-496-1371, Fax: 301-480-1668, E-mail: louis@shiloh.nimh.nih.gov was readily accessible to the students. He often joined some of us on the patio of the Student Union where we usually congregated after lunch, and it was in casual conversations on such occasions that we learned of his interest in the cerebral circulation.

At a symposium on the cerebral circulation held at the 1944 annual FASEB meeting the dominant theme that emerged was the need for a quantitative method for measuring cerebral blood flow (CBF), preferably one applicable to unanesthetized man. Seymour met this challenge with a unique and conceptually brilliant approach. Cournand's had applied the direct Fick principle to the determination of cardiac output in man by using oxygen as a tracer and measuring total body $\mathrm{O}_{2}$ consumption and pulmonary arteriovenous $\mathrm{O}_{2}$ differences in steadystate conditions. Seymour reasoned that he could apply the Fick principle directly by introducing a chemically inert, diffusible tracer into the blood and measuring its cerebral arteriovenous concentration differences in nonsteady states. He used nitrous oxide $\left(\mathrm{N}_{2} \mathrm{O}\right)$ as the tracer, but any chemically inert, diffusible tracer could be used, and radioactive krypton and xenon were used later. Because arterial and cerebral venous blood sampling was required to determine $\mathrm{CBF}$, it was relatively simple to compute also cerebral utilization or production of oxygen, glucose, carbon dioxide, lactate, etc., from the determined $\mathrm{CBF}$ and their measured arteriovenous differences. This was the basis of the Kety-Schmidt $\mathrm{N}_{2} \mathrm{O}$ method for measurement of CBF and metabolism in unanesthetized man which, along with several of its applications, was published in 1948. Its impact revolutionized research on the human brain. Its numerous applications led to much of our knowledge of the physiology and pharmacology of human cerebral circulation and metabolism in health and disease. Carl Schmidt, in whose department Seymour had developed the method, wrote, " . . now, for the first time, the clinical physiologist is no longer at a disadvantage in studying the circulation in the human brain. As matter of fact he is now able to learn more about this, and its relation to the met- 
abolic functions of the organ supplied, than about any other organ of the body. The change is one of the small profits of the research activities of the war years and is one more example of the benefits to be expected from giving brilliant young men opportunities to develop and test out original ideas."

These publications appeared while I was serving in the U.S. Army as a neuropsychiatrist and uncertain about what to do after discharge. The ability to study cerebral blood flow and metabolism in normal and mentally ill humans was appealing. Therefore, when discharged in 1949 I sought and obtained a fellowship with Seymour in the Dept. of Physiology and Pharmacology in the Graduate School of Medicine at Penn where Seymour was now a full professor. It was a fantastic experience. He was an inspiring mentor. It was clear that conceptual thinking, creativity, originality, and uniqueness were what he valued most. He never allowed his towering intellect to intimidate us. He was always open, humble, and unpretentious, listened to everything we had to say, and often raised questions and patiently considered our responses even though, as we would later learn, he already knew the answers.

In 1951 Seymour left Penn to become Scientific Director of the Intramural Research Programs of the then newly established NIMH and NINDB. The NIH Clinical Center was being built, and Seymour had what he thought were almost unlimited resources in space, budget, and positions. He undertook organization of the program in typical Kety fashion, thoughtfully, systematically, and with great humility. He did not presume to know how best to study mental disease but had faith that more basic, fundamental knowledge of the structure and functions of the nervous system was needed. $\mathrm{He}$, therefore, emphasized basic science and relegated most of his resources to laboratories organized along more or less traditional disciplinary lines. To select Laboratory Chiefs he exhaustively consulted leaders in these disciplines, either to recruit them or to identify other outstanding candidates. Laboratory Chiefs were selected not because they had been working in the latest most fashionable areas, but because their previous research demonstrated good conceptual thinking, originality, creativity, and ability to identify and solve good problems. He was not impressed by wish-fulfilling descriptive research driven more by desire than by insight. Once appointed, they were given full authority and support to run their own laboratories as they chose. His acumen in selection of Laboratory Chiefs and of many on their staffs was eventually confirmed by their achievements, one Nobel prize, three Lasker awards, and close to a dozen, if not more, members of the National Academy of Sciences.

Seymour retained a small amount of laboratory space for his own research. The $\mathrm{N}_{2} \mathrm{O}$ method measured only average blood flow and metabolic rates in the brain as a whole and could not localize changes in discrete regions of the brain. He, therefore, undertook development of a method to measure local CBF. Together with several collaborators he ingeniously translated his theory of inert gas exchange into a functional method for measuring local CBF, the ${ }^{131}$ I-labeled trifluoroiodomethane $\left(\mathrm{CF}_{3}{ }^{131} \mathrm{I}\right)$ technique. Localization within the brain was achieved by a unique quantitative autoradiographic technique which limited its use to animals. Its use to determine local CBF in individual structural and functional units of the brain in conscious and anesthetized cats was first reported in 1955. When used to examine the effects of visual stimulation, the autoradiograms clearly visualized the increases in CBF in the visual pathways and provided the first demonstration of functional brain imaging.

Because the $\mathrm{CF}_{3}{ }^{131}$ I method employed autoradiography, it could be used only during uptake of tracer by the tissues. Its basic principles, however, applied also to clearance of tracer from tissues. Seymour had, in fact, reported in 1949 a method to determine muscle blood flow in humans by clearance of ${ }^{24} \mathrm{NaCl}$ from its site of injection. Because ${ }^{24} \mathrm{NaCl}$ is not freely diffusible across the blood:brain barrier, ${ }^{24} \mathrm{NaCl}$ clearance could not be used in brain, but Lassen, Ingvar, and colleagues adapted it for brain by using radioactive gases, first ${ }^{85}$ krypton and subsequently ${ }^{133}$ xenon. The ${ }^{133} \mathrm{Xe}$ method has been extensively and effectively used as a clinical and research tool for decades. More recently, the $\mathrm{CF}_{3}{ }^{131} \mathrm{I}$ method has been resurrected for human use, but the ${ }^{15} \mathrm{O}$-labeled water as the tracer and PET scanning in place of autoradiography and is widely used for functional brain imaging of cognitive processes in humans. All these developments in neurobiology were derived from Seymour's pioneering work.

In 1956 Seymour resigned as Scientific Director and became Chief of the Laboratory of Clinical Science (LCS) where he established a program of research on the biology of schizophrenia. He had been impressed by developments in psychopharmacology, particularly the role of the monamine neurotransmitters and the actions of psychotomimetic drugs (e.g., LSD, mescaline, indoles, etc). There were suggestions at the time that abnormal metabolites of amino acids or of epinephrine might be involved in schizophrenia. There were also reports which, though flawed and inconclusive, suggested genetic influences in schizophrenia. His program was temporarily interrupted in 1961 while he served as Chairman of Johns Hopkins University's Department of Psychiatry, but resumed when he returned after one year to his position of Chief of the LCS, NIMH. This time, however, Seymour focused on genetic contributions to the disease. Previous studies had failed to disentangle convincingly the roles of "nature and nurture." He conceived of the brilliant idea of studying adoptive and biological family lines of schizo- 
phrenics who had been adopted at birth. The necessary data were available in the Danish Case Registry, and, in collaboration with colleagues at the NIMH and in Denmark, he initiated such studies. In 1967 he left NIMH for Harvard University where he first became Director of Psychiatric Research, MGH, then Director of Laboratories for Psychiatric Research, Mailman Research Center, McLean Hospital, and finally Professor of Neuroscience in the Department of Psychiatry. In 1983 he retired from Harvard and returned to the NIMH from which he re-retired in 1996. Throughout all these decades and all his moves he continued his studies on adopted schizophrenics which demonstrated significantly greater incidence of the disease in the biological than in the adoptive family lines and thus produced unequivocal evidence of a major genetic component in the etiology of schizophrenia. These studies represent not only an outstanding contribution to our understanding of schizophrenia, but have provided a research model that has been followed in studies of a number of other psychiatric disorders.

Seymour Kety's legacy encompasses at least three different areas of his endeavors. As a physiologist, he made extraordinary contributions, mainly to the field of cerebral circulation and metabolism but with much broader ramifications. As a wise and adroit statesman, he developed at the NIMH and NINDB outstanding research programs in neuroscience, contributed substantially to the recognition of neurochemistry as an important field of neuroscience, was a powerful force for the development of biological psychiatry, and was a sage counselor on countless advisory boards and committees. Finally, as a psychiatric geneticist, he conceptualized and developed a model of study for distinguishing contributions of nature and nurture in the etiology of mental disease and used it to prove the existence of a strong genetically determined vulnerability to schizophrenia.

There is also Seymour Kety the man. His professional achievements gained him international recognition, fame, and acclaim. He received many awards and honorary degrees and was elected into some of the most honorific societies, including the U.S. National Academy of Sciences, American Academy of Arts and Sciences, and American Philosophical Society. His last award was in 1999, the Lasker Award for Special Achievement in Medical Science, which touched him deeply. None of these honors changed him. He remained the same humble, modest, self-effacing, unselfish, considerate, generous, and warm human being that he was 56 years ago when I first met him.

Seymour is survived by his wife Josephine (Gross) Kety, daughter Roberta Kety, son Lawrence Kety, and two grandchildren. He will be greatly missed not only by them, but by his many colleagues and friends whose lives he influenced and enriched.

Louis Sokoloff, M.D.

Laboratory of Cerebral Metabolism National Institute of Mental Health Bethesda, Maryland 20892 